\title{
Calculation of airgap function and inductance using analytical modeling of rotor magnetic characteristics of an IPM motor under loaded condition
}

\author{
Binita Nanda and Praveen Kumar \\ Department of Electronics and Electrical Engineering \\ Indian Institute of Technology Guwahati \\ Guwahati - 781039, Assam, India \\ Email: \{binita.nanda, praveen_kumar\}@iitg.ac.in
}

\begin{abstract}
The permanent magnet (PM) motors are widely used in electric vehicle (EV) applications due to their high power density. The EV motor should be capable of a wide wide operating speed Range (WOSR) to meet the vehicle's traction torque demand. One way to achieve the wide speed range operation in PM motors are by using field weakening. The PM motors' field weakening capacity depends on the saliency ratio. The saliency ratio is given by the ratio of the direct and quadrature axis inductance $\left(L_{d}, L_{q}\right)$. A high saliency ratio will result in wide speed range operation. Hence, the rotor geometry has to be designed carefully to enable operation at high speeds. This paper proposes an analytical model to calculate the airgap function and inductance, which can be used to get an optimal design during the initial design phase. The results of the presented analytical model are compared with FEM and measurements and it is shown that the method is accurate enough for initial optimisation of IPMSMs.
\end{abstract}

\section{INTRODUCTION}

Electric vehicles being a cleaner form of transport, is on the verge of experiencing rapid growth in developed and developing vehicle markets. One of the essential parts of the EV drive train, besides the battery pack, is the motor. The EV motor must be compact and light due to the limited mounting space in the vehicle. Moreover, the motor should have low cogging torque and low torque ripple for driving comfort and a smooth start. The most commonly used motor in EVs is the interior permanent magnet (IPM) motor. IPMs are preferred due to their high power and torque density, good efficiency and excellent field weakening capability [1]. The field weakening capability of IPMs results in Wide Operating Speed Range (WOSR). WOSR is critical to meet the vehicle's varying traction torque demand. A high saliency ratio, which is a function of rotor geometry, in the IPM motors results in WOSR.

The relation between the design parameters of the rotor and the motor performance can give insight into an optimal motor design for a motor designer . In IPM motor, achieving a high saliency ratio is a desirable factor in the rotor design. Saliency in IPM motors arises from inset PMs in the rotor, resulting in a non-uniform air gap with a nonequal direct axis and quadrature axis reluctance. This results in nonequal direct and quadrature axis inductance $\left(L_{d}, L_{q}\right)$ [2]. These inductances are used in analytical models to estimate motor performance.

In [3], a sequential-stage MEC (SSMEC) that considers the magnetic saturation effect in the iron core, the slotting effect, and the on-load characteristics of IPMSMs is proposed. However, the effect of rotor geometrical parameters on the rotor magnetic characteristics of the motor performance cannot be captured using the MEC model. Hence using MEC, the accurate analysis of the motor behaviour becomes difficult at load conditions with a high degree of magnetic saturation. The Finite-element analysis (FEA) provides a solution for accurate analysis of motor performance [4]. However, during the initial stage of machine design, the FEM is cumbersome and computationally expensive. Thus, FEM is usually employed as a validation tool in the form of commercial software packages.

A simplified and accurate model is proposed to capture the nonlinear variation of inductances with current. The model is developed using a combined rotor saturation map (RSM) and a nonlinear MEC model. An initial design of a V-shaped IPM rotor is considered and its geometrical relationships are derived. A non-uniform local saturation map in the rotor iron is proposed using the PM flux paths under no-load condition [5] [6]. The proposed geometrical saturation map and the MEC are used to develop a mathematical model for an IPM motor at loaded conditions. The proposed hypothesis is validated by FEA and experimental results for a prototyped $1 \mathrm{KW}$ IPM motor.

The contributions of this work are:

- To develop an analytical model of the magnetic characteristics of an IPM motor such as stator and rotor spatial field distributions, the equivalent airgap function, stator MMF, and rotor PM flux density.

- To estimate and capture the nonlinear variation of inductances with current using the proposed analytical model.

The paper's organisation is as follows; in section II, the initial design parameters of a V-shaped IPM are presented, and the RSM is proposed. In section III, the MEC of the motor is presented. In section IV, the nonlinear model is developed, which uses the MEC and RSM. In section V, the motor 
parameters like airgap function and inductance are calculated using the proposed model.

\section{DESCRIPTION OF THE MOTOR GEOMETRY AND RSM}

The proposed model is developed using a geometrical saturation map and the MEC for an IPM motor at loaded condition. In this section, an initial design of a V-shaped IPM rotor is considered, and its geometrical relationships are derived. The regions above the magnet pockets are the most critical because it is magnetically saturated [7]. A non-uniform local saturation map in the rotor iron is proposed using the PM flux paths under no-load condition. The initial IPM motor design and the rotor saturation map is discussed in the following subsections.

\section{A. Motor geometry}

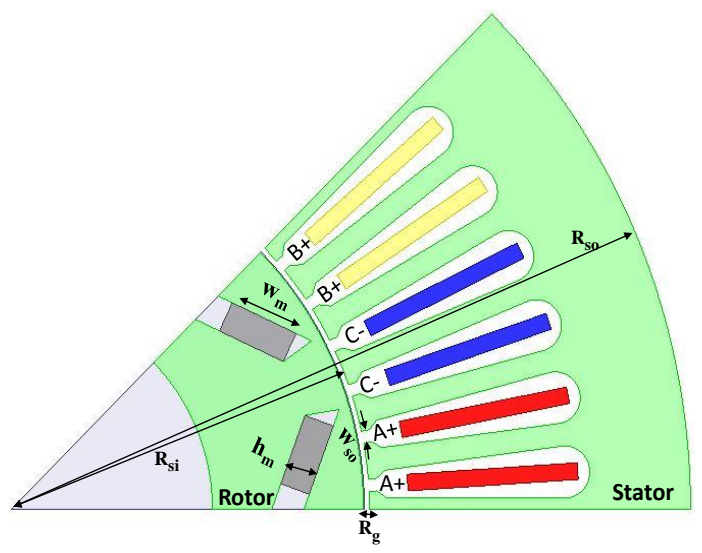

Fig. 1.8 pole 48 slots IPM

An initial design of a V-shaped IPM motor is considered as shown in Fig. 1. The motor design design parameters are given in Table I.

TABLE I

MOTOR PARAMETERS

\begin{tabular}{llll}
\hline \hline Parameters & Value & Parameters & Value \\
\hline Rated power $\left(P_{\text {rated }}\right)$ & $0.75 \mathrm{KW}$ & Rated current $\left(I_{\text {rated }}\right)$ & $3 \mathrm{~A}$ \\
Rated speed $\left(N_{\text {rated }}\right)$ & $750 \mathrm{rpm}$ & Number of poles $(p)$ & 8 \\
Number of stator slots $\left(N_{s}\right)$ & 48 & Number turns per coil $(N)$ & 70 \\
Stator phase resistance $\left(R_{s}\right)$ & $7 \Omega$ & Slot opening width $\left(w_{s o}\right)$ & $1.2 \mathrm{~mm}$ \\
Stator inner radius $\left(R_{s i}\right)$ & $35.6 \mathrm{~mm}$ & Stator outer radius $\left(R_{s o}\right)$ & $67.5 \mathrm{~mm}$ \\
Air gap $(g)$ & $0.6 \mathrm{mmm}$ & stack length $\left(l_{s t}\right)$ & $65 \mathrm{~mm}$ \\
Offset distance of pocket from thr centre $\left(O_{p}\right)$ & $25.896 \mathrm{~mm}$ & pole arc angle $(\beta)$ & $34{ }^{0}$ \\
Magnet width $\left(w_{m}\right)$ & $7 \mathrm{~mm}$ & Smaller length of pocket $\left(l_{p 1}\right)$ & $9.64 \mathrm{~mm}$ \\
Larger length of pocket $\left(l_{p 2}\right)$ & $10.25 \mathrm{~mm}$ & Pocke gap $\left(g_{p}\right)$ & $3.2 \mathrm{~mm}$ \\
V-angle from base $(\alpha)$ & $20^{0}$ & Peak value of no load flux linkage $\left(\lambda_{p m}\right)$ & $0.249 \mathrm{~Wb}$ \\
\hline
\end{tabular}

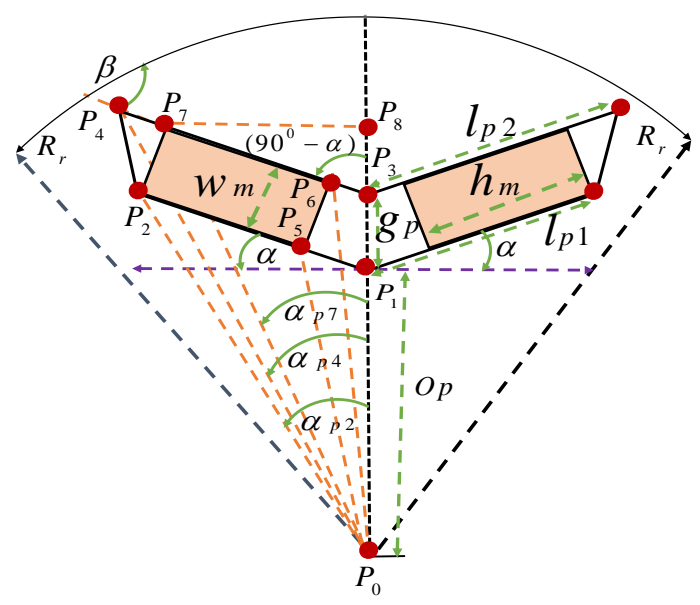

Fig. 2. Geometry of a V-shaped IPM pole

The geometrical relationships in a V-shaped IPM rotor are given in Table II. The geometrical relationships are derived using Fig. 2 with the known input geometrical design parameters given in Table I.

TABLE II

GEOMETRICAL RELATIONSHIPS IN V-SHAPED IPM

\begin{tabular}{|c|c|c|c|}
\hline Lengths & Equation & Angle & Equation \\
\hline$P_{0} P_{2}$ & $\sqrt{l_{p 1}^{2}+O_{p}^{2}-2 l_{p 1} O_{p} \cos (\alpha+90)}$ & $\alpha_{p 2}$ & $\cos ^{-1}\left(\frac{P_{0} P_{2}{ }^{2}+O_{p}{ }^{2}-l_{p 1}{ }^{2}}{2\left(P_{0} P_{2}\right)\left(O_{p}\right)}\right)$ \\
\hline$P_{0} P_{4}$ & $\sqrt{2_{p 1}^{2}+O_{p}^{2}-2 l_{p 2} O_{p} \cos (\alpha+90)}$ & $\alpha_{p 4}$ & $\cos ^{-1}\left(\frac{P_{0} P_{4}^{2}+O_{p}^{2}-l_{p 2}{ }^{2}}{2\left(P_{0} P_{4}\right)\left(O_{p}\right)}\right)$ \\
\hline$P_{0} P_{5}$ & $\sqrt{P_{1} P_{5}^{2}+O_{p}^{2}-2 P_{1} P_{5} O_{p} \cos (\alpha+90)}$ & $\alpha_{p 5}$ & $\cos ^{-1}\left(\frac{P_{0} P_{5}^{2}-P_{1} P_{5}^{2}+O_{p}^{2}}{2\left(P_{0} P_{5}\right)\left(O_{p}\right)}\right)$ \\
\hline$P_{0} P_{7}$ & $\sqrt{P_{0} P_{8}^{2}+P_{7} P_{8}^{2}}$ & $\alpha_{p 7}$ & $\tan ^{-1}\left(\frac{P_{7} P_{8}}{P_{0} P_{8}}\right)$ \\
\hline
\end{tabular}

The B-H curve of the motor lamination material 50C350 obtained by Epstein frame method is given in Fig. 3(a). The knee value of the relative permeability of the material is found to be 50 at $B_{\text {sat }}$ value of $1.6 \mathrm{~T}$.

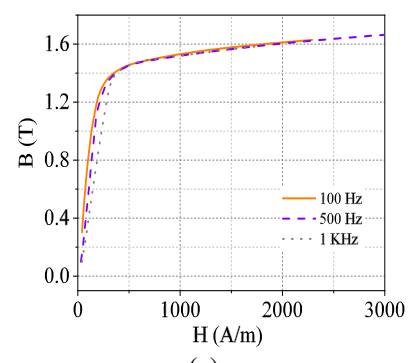

(a)

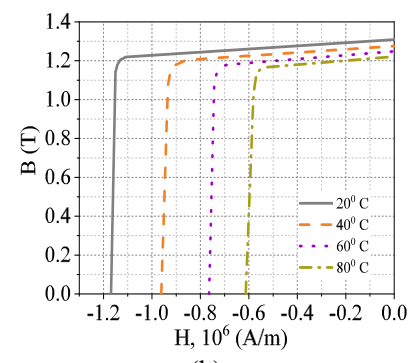

(b)
Fig. 3. B-H curve of (a) lamination material 50C350 (b) Permanent magnet $\mathrm{NdFeB}$.

The PMs used are rare earth magnets $(\mathrm{NdFeB})$. The second quadrant B-H characteristics of the $\mathrm{NdFeB}$ is shown in Fig. 3(b). 


\section{B. Rotor areas}

Aimed at maximizing the power density, the IPM rotor is designed to be partially saturated in the bridge areas to steer the PM flux into the airgap [5]. The flux line paths are shown in Fig. 4(a).

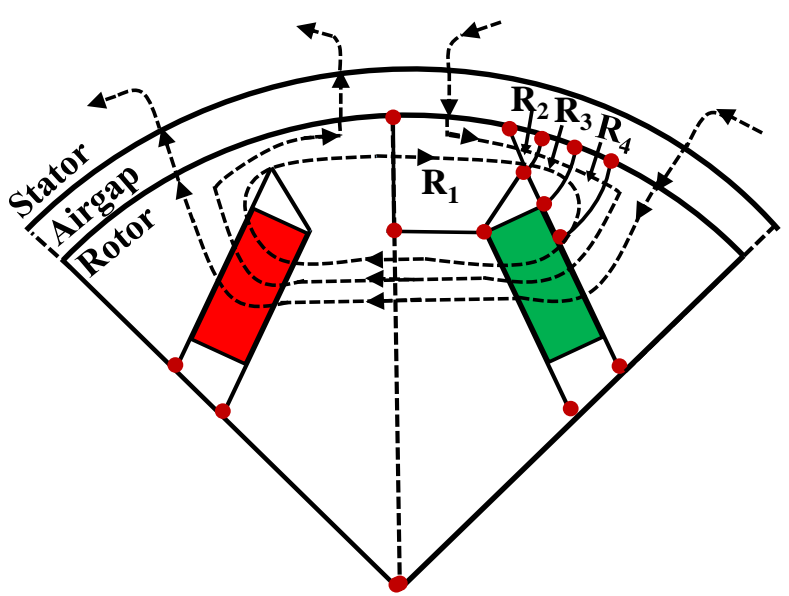

(a)

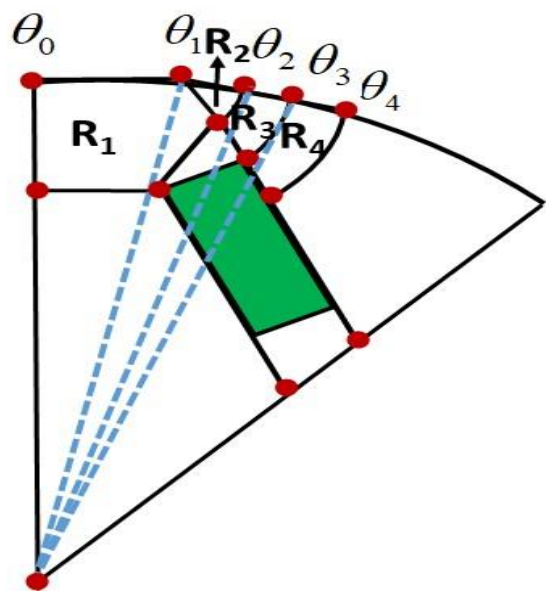

(b)

Fig. 4. (a) Flux line paths (b) Rotor saturated areas $\left(R_{1}-R_{4}\right)$

The saturation map in the rotor is divided into four areas named $R_{1}, R_{2}, R_{3}$, and $R_{4}$ as shown in Fig. 4(b).

The lengths and areas of airgap flux lines passing through the saturated rotor regions are derived using the geometrical calculations using Fig. 5. Table III shows the derived equations of airgap lengths $\left(W_{n}\right)$ and areas $\left(A_{n}\right)$ of the four saturated rotor regions $\left(R_{1}-R_{4}\right)$.

It can be seen from Fig. 4(b) that $\theta_{4}$ is the rotor peripheral angle of the differential arc where the flux density decreases to a point when saturation becomes negligible. This angle depends on the rotor geometry and the B-H curve of the lamination material.

The proposed geometrical saturation map will be used to calculate the parameters to solve the MEC, which is discussed in the subsequent sections.

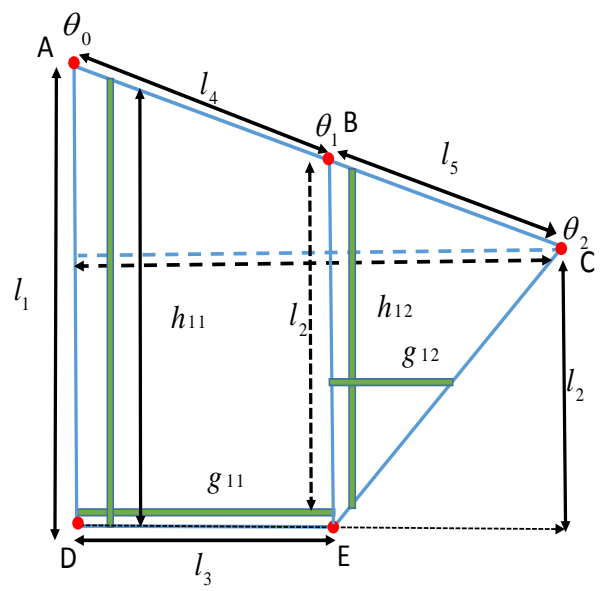

(a)

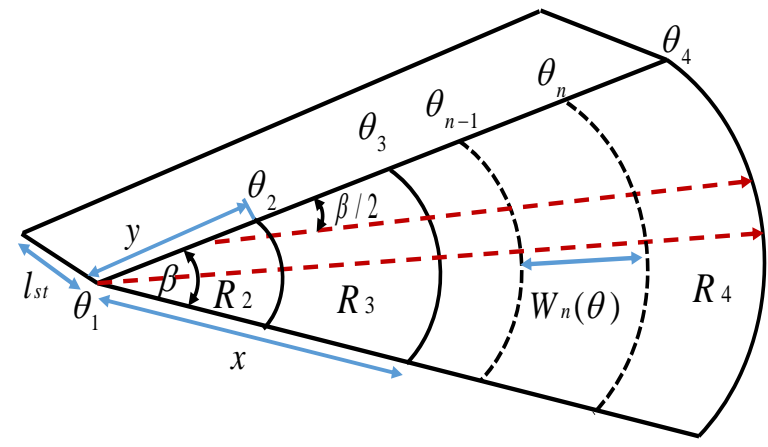

(b)

Fig. 5. Geometry for area amd airgap length calculation in (a) Region $1\left(R_{1}\right)$ (b) Region 2 to Region $4\left(R_{2}-R_{4}\right)$

TABLE III

AIRGAP LENGTH AND AREA CALCULATIONS FOR THE SATURATED ROTOR REGIONS $\left(R_{n}\right)[5]$

$W_{1}=\left(g_{11}+g_{12}\right) \quad A_{1}=\left(h_{11}+h_{12}\right) l_{s t}$

$W_{n}(\theta) \quad \sqrt{\left(\theta_{n}-\theta_{1}\right)^{2} R_{r}{ }^{2}-y^{2}(\sin (\beta / 2))^{2}}-y \cos (\beta / 2), \mathrm{n}=2 \ldots 4$

$A_{n} \quad \frac{1}{2}\left(\beta\left(\theta_{n}-\theta_{1}\right) R_{r}+\beta\left(\theta_{n-1}-\theta_{1}\right) R_{r}\right) l_{s t}, \mathrm{n}=2 \ldots 4$

\section{MEC OF THE MOTOR}

MEC is a magnetic reluctance network of a motor based on the path the flux lines take in the machine geometry [8]. MEC can take into account the non-linear B vs. H curve of the ferromagnetic material [9]. In this work, the non linear MEC is considered to capture the nonlinaer behavior of the motor due to nonlinear B-H curve of the lamination material. The nonlinear MEC of the motor is developed in the following subsections. 


\section{A. MEC at noload}

The airgap flux density is calculated using the motor geometrical parameters and the local saturation map in the rotor iron [6]. The magnetic flux density distribution $B_{p m}$ shown in Fig. 6, is given as:

$$
B_{p m}\left(t, \theta_{s}\right)=\sum_{n=\frac{p}{2} m} B_{\max _{n}} \sin \left(n w_{r} t-n \theta_{s}\right), m=1,3,5 \ldots
$$

where,

$$
B_{\max _{n}}=\frac{p B_{m}\left(\sin \left(n \theta_{4}\right)-\sin \left(n \theta_{1}\right)\right)}{2 n^{2} \pi\left(\theta_{4}-\theta_{1}\right)}
$$

where, $B_{m}$ is the maximum value of flux density due to PMs. The relative permeance function being simple, fast and accurate is used here to account for slotting effect [10]. $\phi_{s}$ denotes the initial rotor position. The airgap flux linkage at no load $\left(\Phi_{g}\right)$ is calculated using the MEC at no load [6].

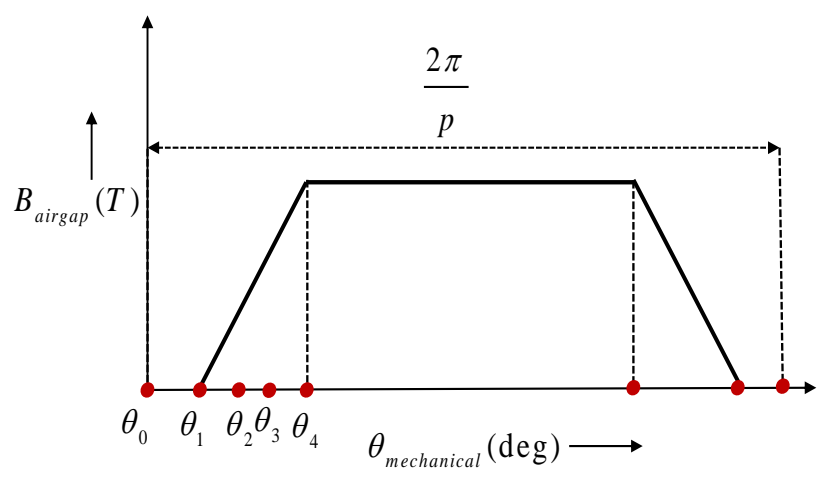

(a)

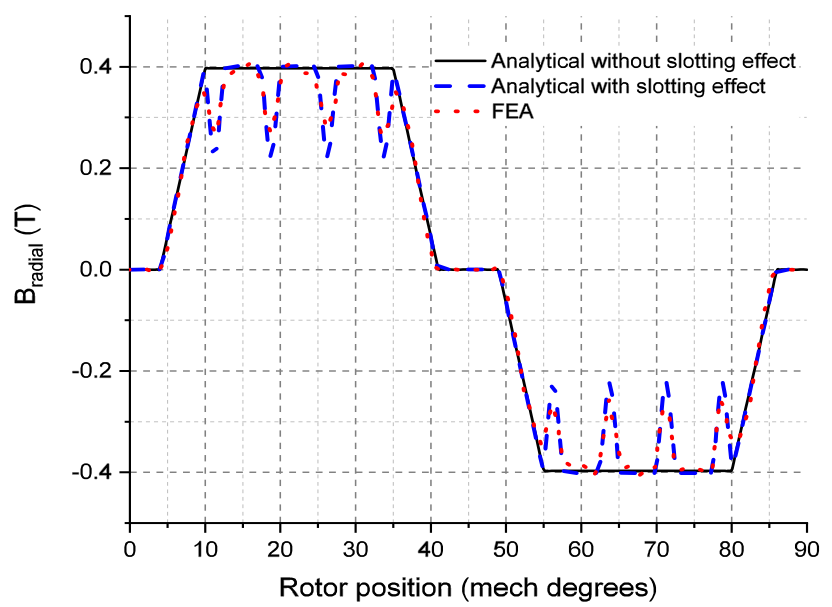

(b)

Fig. 6. Airgap field distribution (a) Trapezoidal PM flux density (b) Noload airgap flux density.

The airgap flux due to PMs can be calculated as:

$$
\phi_{g}=l_{s t} \int_{0}^{\frac{2 \pi}{2 p}} B_{p m}\left(t, \theta_{s}\right)\left(R_{r}+\frac{g}{2}\right) d \theta_{r}
$$

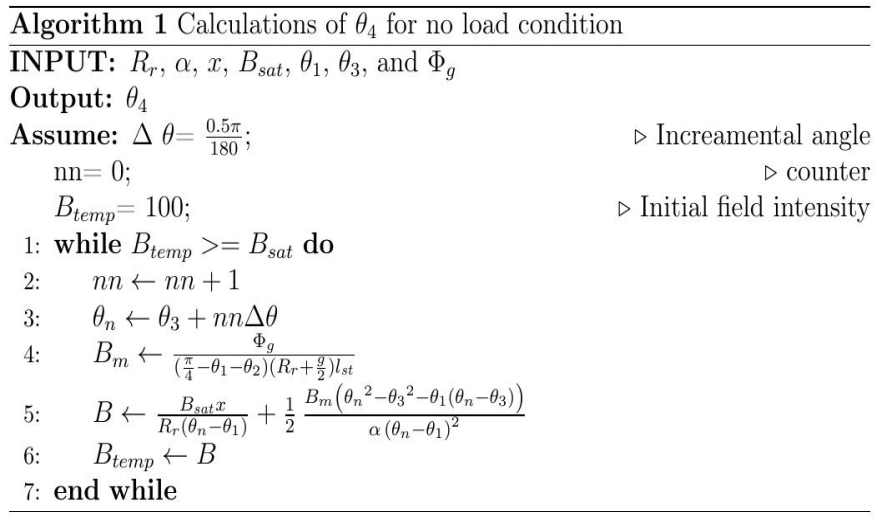

Fig. 7. Algorithm for $\theta_{4}$ calculation at no load

$$
\phi_{g}=B_{m}\left(\frac{\pi}{4}-\theta_{1}-\theta_{4}\right)\left(R_{r}+\frac{g}{2}\right) l_{s t}
$$

As discussed earlier the knee value of relative permeability i.e 50 at $B_{\text {sat }}$ of $1.6 \mathrm{~T}$ from the B-H curve, is used to calculate $\theta_{4}$. The algorithm for $\theta_{4}$ calculation is given in Fig. 7. From Table III, it can be seen that $A_{4}$ varies with load as $\theta_{4}$ changes with load with increase in saturation. The no load flux in the region $4\left(\phi_{A 4_{N L}}\right)$ is given as:

$$
\phi_{A 4_{N L}}=B_{s a t} A_{4_{N L}}
$$

\section{B. MEC at load}

In this subsection, the MEC of the motor when only due to the stator current is presented. Due to saliency, the magnetic airgap as seen by the stator flux is not uniform. Due to non-uniform airgap, the reluctance seen by A phase flux is maximum when the rotor $\mathrm{d}$-axis aligns with phase $\mathrm{A}$ and minimum when the rotor $\mathrm{q}$-axis aligns with phase A. Fig. 8(a) and Fig. 8(b) gives an illustrative explanation of rotor $\mathrm{q}$ and $\mathrm{d}$ axis alignment with stator A phase axis, respectively.

The MECs are different for the two alignment conditions because the reluctance seen by the phases is different. The rotor magnets are switched off. The MEC due to the stator current with d-axis and q-axis alignment are shown in Fig. 10 and Fig. 11, respectively.

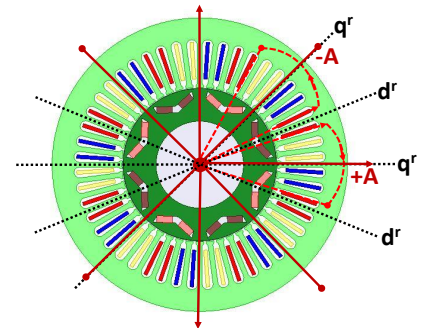

(a)

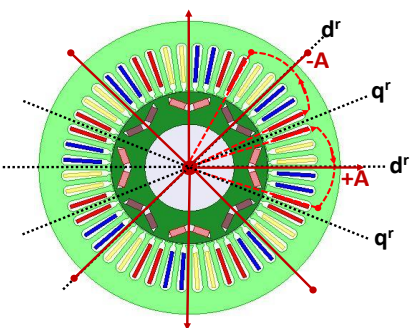

(b)
Fig. 8. Explanation of physical A axis alignment with: (a) q axis of rotor (b) d-axis of rotor. 


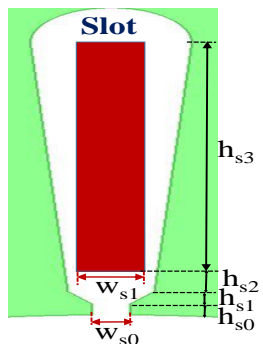

(a)

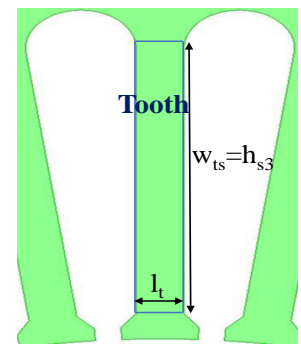

(b)
Fig. 9. Reluctance calculation parameters for: (a) slot (b) tooth.

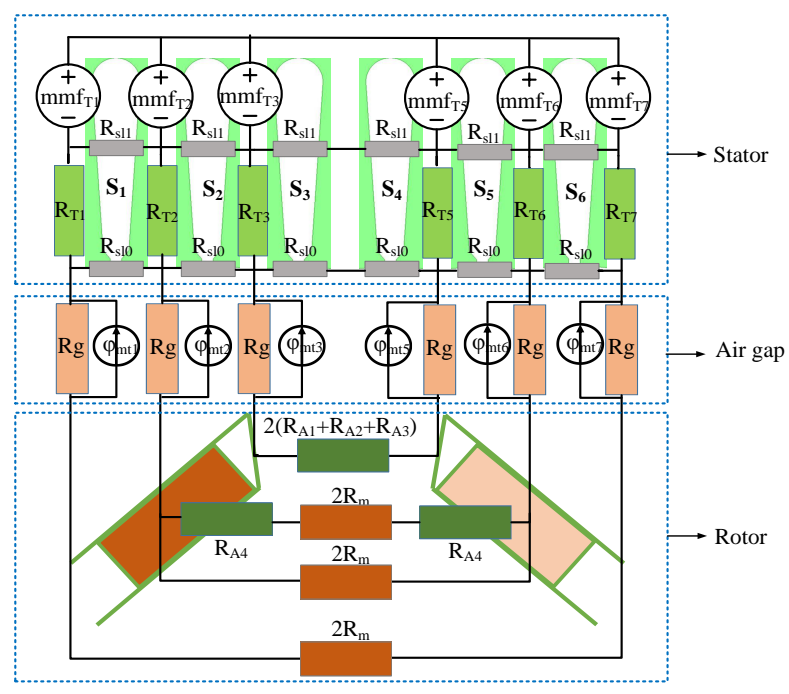

Fig. 10. Stator excitation only with magnets turned off: MEC for d-axis alignment.

The MEC in Fig. 10 and Fig. 11 takes into account the stator leakage. The various reluctances are as follows:

$R_{s c}$ : Reluctance of the rotor yoke.

$R_{p m}$ : Reluctance of the permanent magnets.

$R_{g}$ : Reluctance of the airgap.

$R_{T 1-T 7}$ : Reluctance of the stator tooth.

$R_{A 1-A 4}$ : Reluctance of the saturated regions $\left(R_{1}-R_{4}\right)$ in the rotor.

$R_{s l 0}$ : Reluctance at the slot opening.

$R_{s l 1}$ : Reluctance at the middle of slot.

TABLE IV

SLOT AND TOOTH GEOMETRY PARAMETERS (IN MM)

\begin{tabular}{llllllll}
\hline \hline$w_{s 0}$ & $w_{s 1}$ & $h_{s 0}$ & $h_{s 1}$ & $h_{s 2}$ & $h_{s 3}$ & $l_{t}$ & $w_{t s}$ \\
\hline 1.2 & 2.68 & 0.8 & 0.88 & 2.18 & 17 & 2.2 & 17 \\
\hline
\end{tabular}

The slot geometry is shown in Fig. 9. The slot and tooth design parameters are given in Table IV. The reluctances at the slot opening $\left(R_{s l 0}\right)$ and at the middle of the slot $\left(R_{s l 1}\right)$ can be obtained using specific slot permeance $P_{s l 0}$ and $P_{s l 1}$, respectively, which is given as [11]:

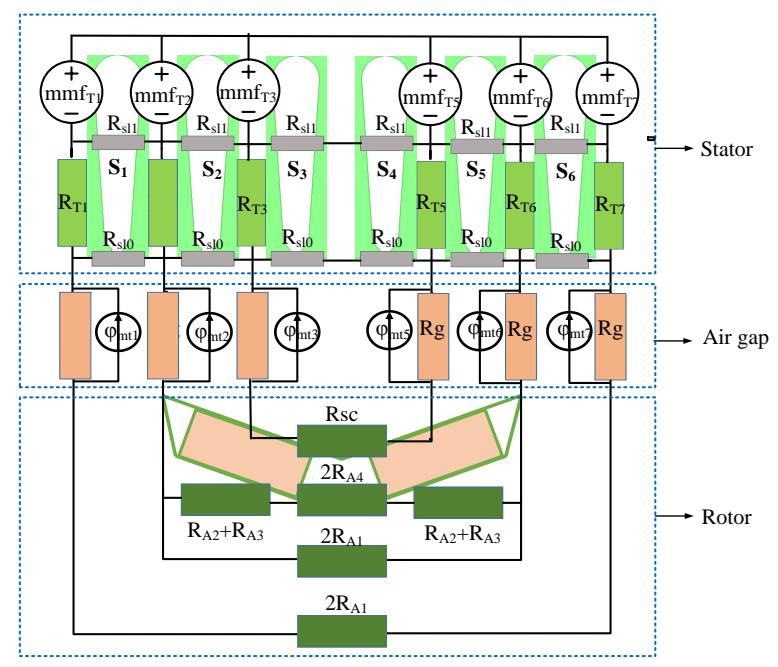

Fig. 11. Stator excitation only with magnets turned off: MEC for q-axis alignment.

$$
\begin{gathered}
P_{s l 0}=\frac{h_{s 2}}{w_{s 1}}+\frac{h_{s 1}}{w_{s 1}+w_{s 0}}+\frac{h_{s 0}}{w_{s 0}} \\
P_{s l 1}=\frac{h_{s 3}}{3 w_{s 1}}
\end{gathered}
$$

The formulas and values of reluctances used in the MECs in Fig. 10 and Fig. 11 are given in Table V.

TABLE V

RELUCTANCE CALCULATION FOR MEC

\begin{tabular}{cc|cc}
\hline \hline Reluctance & Values (AT/Wb) & Reluctance & Values (AT/Wb) \\
\hline$R_{g}=\frac{2}{3} \frac{g}{\mu_{0} \gamma\left(R_{r}+\frac{g}{2}\right) l s t}$ & $3.53 \times 10^{5}$ & $R_{m}=\frac{W_{m}}{\mu_{0} \mu_{p m} h_{m} l_{s t}}$ & $5 \times 10^{6}$ \\
$R_{s l 0}=\frac{P_{s l 0}}{\mu_{0} l_{s t}}$ & $6.3 \times 10^{6}$ & $R_{s l 1}=\frac{P_{s l 1}}{\mu_{0} l_{s t}}$ & $5.8 \times 10^{6}$ \\
$R_{t s}=\frac{w_{t s}}{\mu_{0} \mu_{t s} l_{s t} l_{s t}} ; s=1 . .7$ & $1688\left(\mu_{t s}=500\right)$ & $R_{s c}=\frac{l_{y k}}{\mu_{0} \mu_{y k} A_{y k}}$ & 5000 \\
$R_{A n}=\frac{g_{n}}{\mu_{0} \mu_{s a t} A_{n}} ; n=1 . .4$ & $R_{A 1}=2.4 \times 10^{5}$ & $R_{A 2}=6.5 \times 10^{5}$ & $R_{A 3}=2.3 \times 10^{5}$ \\
\hline
\end{tabular}

From Fig. 10 and Fig. 11, it can be seen that there is an MMF source in each tooth and flux source in the airgap. The MMF source in the tooth is due to the current in the stator winding. The flux source in the airgap is due to PM. The details of determining the MMF source and the flux sources are discussed in the following subsections.

\section{Rotor's B field consideration in MEC}

To determine the equivalent flux source, it is necessary to know the flux density distribution in the airgap only due to magnets. The magnetic flux density distribution $B_{p m}$ shown in Fig. 6(b), is integrated over a slot pitch to get the noload flux $\left(\phi_{t s N L}\right)$ in each tooth.

From Fig. 8(a) and Fig. 8(b), it can be seen that $\phi_{s}=0^{0}$ for q-axis alignment and $\phi_{s}=22.5^{0}$ for d-axis alignment.

The flux for each tooth $\phi_{m t s}$ due to PMs is given by: 


$$
\phi_{t s N L}=l_{s t} \int_{0}^{\tau_{s}} B_{p m}\left(t, \theta_{s}\right)\left(R_{r}+\frac{g}{2}\right) d \theta_{r}
$$

where, $\tau_{s}$ is the slot pitch.

\section{Stator winding conversion}

To determine the tooth MMF in Fig. 10 and Fig. 11, the actual stator winding, which is distributed, has to be converted to concentrated winding. The MMF of any closed path in a magnetic circuit is defined as the net ampere-turns enclosed by that path. The phase MMF distribution of the actual stator winding is derived by taking into account the linear rise of MMF across the slot.

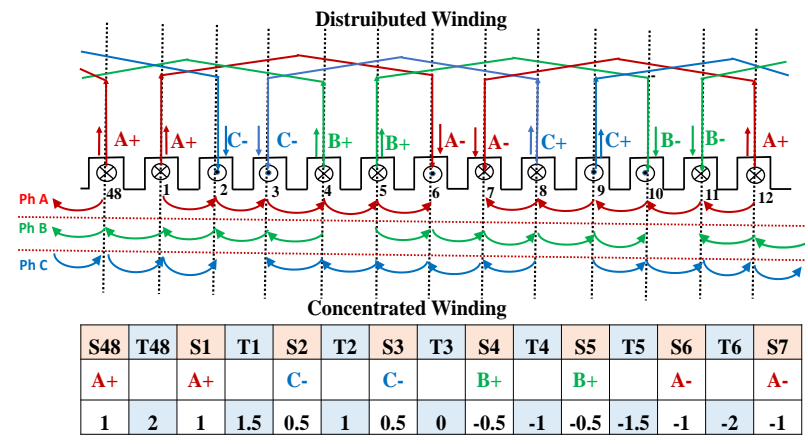

Fig. 12. Conversion of distributed winding to concentrated winding.

The winding is converted into equivalent concentrated winding (also known as single tooth) [12]. The details of the conversion are explained in Fig. 12. For the concentrated winding shown in Fig. 12, the MMF of each coil is calculated as follows:

- Assume that the phase A current is $1 \mathrm{~A}$, and the phase B and $\mathrm{C}$ currents as $-0.5 \mathrm{~A}$. For simplification, the number of turns is assumed to be 1 .

- The MMFs of each tooth is calculated by adding the MMFS of the left and right slots of that tooth, as shown in Fig. 12. The calculated MMFs are given in Table VI.

TABLE VI

CALCULATED MMFS IN THE STATOR TOOTH DUE TO STATOR EXCITATION USING SINGLE TOOTH WINDING.

\begin{tabular}{lllllll}
\hline \hline$m m f_{T 1}$ & $m m f_{T 2}$ & $m m f_{T 3}$ & $m m f_{T 4}$ & $m m f_{T 5}$ & $m m f_{T 6}$ & $m m f_{T 7}$ \\
\hline$N I_{\max }$ & $1.5 N I_{\max }$ & $N I_{\max }$ & 0 & $-N I_{\max }$ & $-1.5 N I_{\max }$ & $-N I_{\max }$ \\
\hline
\end{tabular}

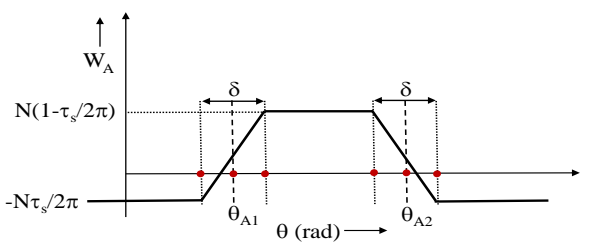

Fig. 13. Winding function of a stator coil including effect of linear rise of MMF across the slots.
The winding function $\left(W_{A}\right)$ of a coil with $\mathrm{N}$ turns and stator slot opening width of $\delta$ radians is given as [13]:

$$
W_{A}(\theta)= \begin{cases}\frac{N}{2 \pi \delta}\left[2 \pi\left(\theta-\theta_{A 1}\right)+\delta\left(\pi-\tau_{s}\right)\right], & \theta_{A 1}-\frac{\delta}{2} \leq \theta<\theta_{A 1}+\frac{\delta}{2} \\ N\left(1-\frac{\tau_{s}}{2 \pi}\right), & \theta_{A 1}+\frac{\delta}{2} \leq \theta<\theta_{A 2}-\frac{\delta}{2} \\ N\left[\left(1-\frac{\tau_{s}}{2 \pi}\right)+\frac{\theta_{A 2}-\theta}{\delta}-\frac{1}{2}\right], & \theta_{A 2}-\frac{\delta}{2} \leq \theta<\theta_{A 2}+\frac{\delta}{2} \\ -N \frac{\tau_{s}}{2 \pi}, & \text { otherwise }\end{cases}
$$

where, $\tau_{s}=\left(\theta_{A 2}-\theta_{A 1}\right)$ is the coil pitch.

The winding function of a stator coil is shown in Fig. 13.

\section{SOlution OF MEC}

In the previous section, the layout and the relevant equations of the MEC for the considered motor was discussed. In the subsequent subsections the solution method and the consideration of the non-linearity of $\mathrm{B}$ vs $\mathrm{H}$ curve of the ferromagnetic material is discussed.

\section{A. Solution Method}

Using the electrical circuit analogy, the mmf sources in each tooth is converted to a voltage source, and the flux sources in the airgap is converted to the current source. The solution of MECs in Fig. 10 and Fig. 11 is done in two steps.

- In the first step flux in the different sections of the motor, represented by the reluctances, are determined using only the stator mmf. This implies that the flux sources are open- circuited.

- In the second step, the flux in different parts of the motor are determined due to the current sources. This implies that the teeth mmf sources are short- circuited.

Eventually, the flux from the steps are added, taking care of the signs, to find the net flux.

The flux in region 4 at load (only stator excitation) $\phi_{A 4_{L}}$ is calculated solving the MEC. The value of $\theta_{4_{L}}$ during only stator excitation can be found as:

$$
\begin{gathered}
\phi_{A 4_{L}}=B_{s a t} A_{4_{L}} \\
A_{4_{4}}=\frac{1}{2} \beta R_{r} l_{s t}\left(\left(\theta_{4_{L}}-\theta_{1}\right)+\left(\theta_{3}-\theta_{1}\right)\right)
\end{gathered}
$$

Substituting eq(11) in eq(10), $\theta_{4_{L}}$ can be calculated as:

$$
\theta_{4_{L}}=\frac{2 \phi_{A 4_{L}}}{B_{\text {sat }} \beta R_{r} l_{s t}}-\theta_{3}+2 \theta_{1}
$$

\section{B. MEC Simplification}

The MEC of Fig. 10 and Fig. 11 has slot leakage reluctance. A simplified MEC without the slot leakage reluctance is shown in Fig. 14. The analysis shows that the MECs of Fig. 10 and Fig. 11 gives results that are close to MECs in Fig. 14. Hence, the leakage terms can be neglected. For the presented model, the MECs in Fig. 14 is considered.

The above explanation is for the constant permeability of the ferromagnetic material. However, the material's permeability is not constant due to the nonlinearity of the $\mathrm{B}$ vs $\mathrm{H}$ curve. 


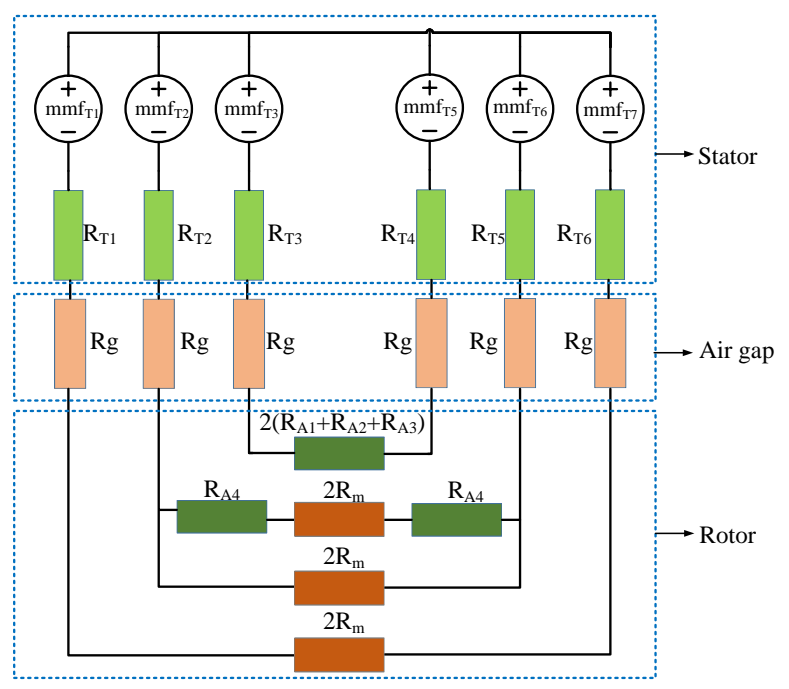

(a)

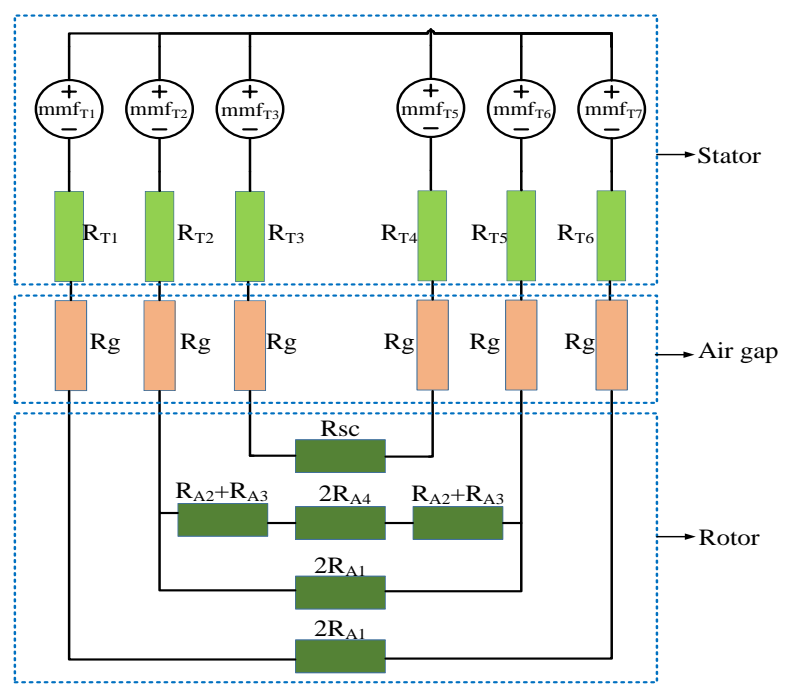

(b)

Fig. 14. Stator excitation neglecting slot leakage with magnets turned off: (a) MEC for d-axis alignment (b) MEC for q-axis alignment.

Hence, the calculation procedure has to be enhanced to include nonlinearity, and it is discussed in the flowing subsection.

\section{Nonlinearity of $B$ vs. $H$ in $M E C$}

The inclusion of MEC has an impact not only on the flux magnitude in the various parts of the motor, but also in the airgap field distribution due to PMs. The permeability is made a function of flux density from the B-H datasheet of the motor.

The permeability of the stator teeths are calculated as:

$$
\mu_{t s}=f\left(B_{t s}\right)
$$

where,

$$
B_{t s}=\frac{\Phi_{t s}}{l_{t s} l_{s t}}
$$

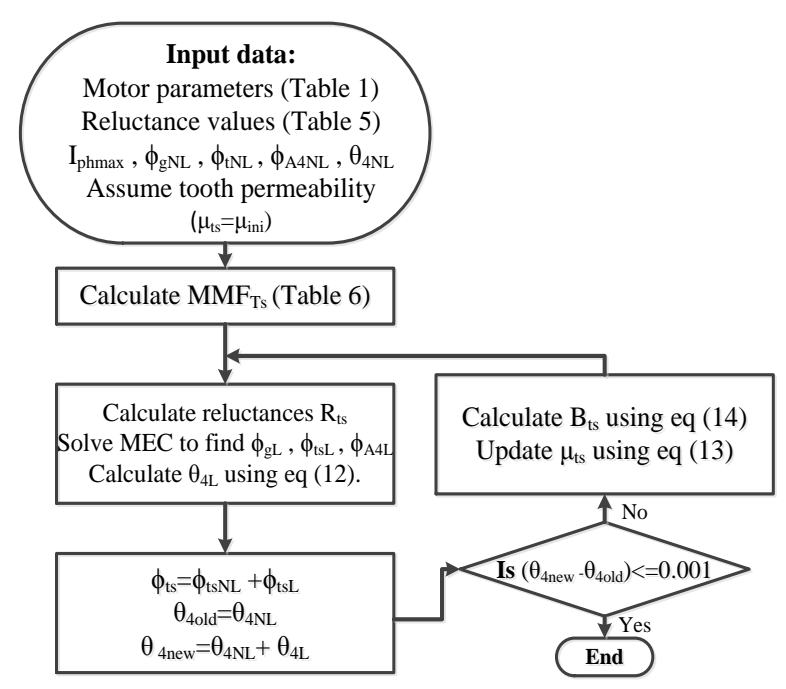

Fig. 15. Overall flow chart for solution of nonlinear MEC

The flowchart for solving the nonlinear MEC is shown in Fig. 15. The plot of $\theta_{4}$ calculated using nonlinear MEC at different currents during $\mathrm{d}$ and $\mathrm{q}$-axis alignments is shown in Fig. 16. In the next section the calculation of motor parameters are discussed.

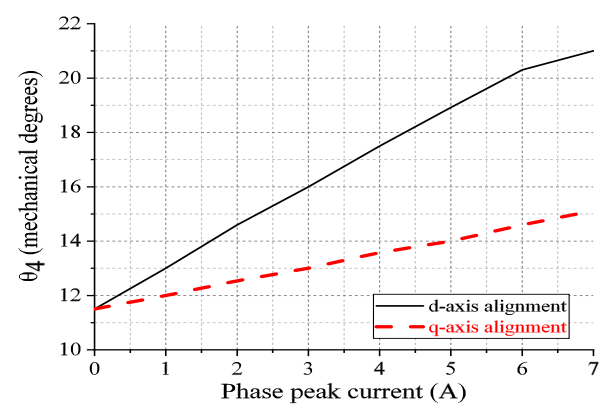

Fig. 16. Increase in saturation in Region $4\left(\theta_{4}\right)$ with increase stator current.

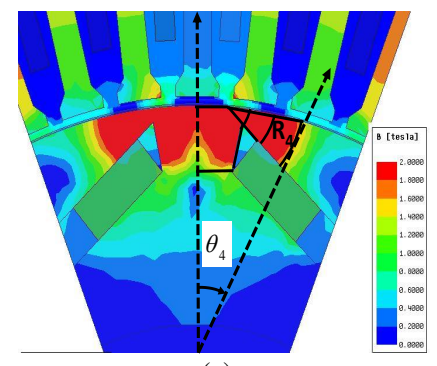

(a)

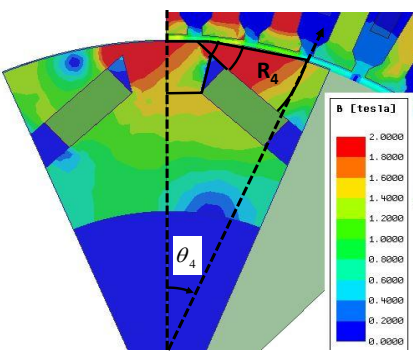

(b)
Fig. 17. B-field density distribution at 4A (rms): (a) along d-axis (b) along q-axis

\section{INDUCTANCE CALCULATION}

This section explains the calculation of equivalent airgap length, and inductance using the motor geometry parameters. 


\section{A. Equivalent air gap}

The magnetic saturation due to rotor geometry changes the physical airgap length. This is called the equivalent airgap length or the magnetic airgap length. Due to saliency, there exist two different eqivalent airgap length seen by per phase stator winding: $g_{q n}$ when the rotor q-axis aligns to that phase and $g_{d n}$ when the rotor d-axis aligns to that phase.

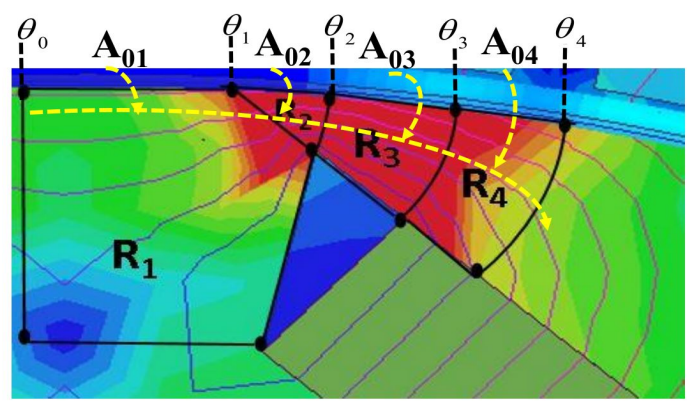

Fig. 18. Fluxline paths from airgap into saturated regions of rotor.

The equivalent airgap lengths along rotor $\mathrm{q}$ and $\mathrm{d}$ axis are calculated as:

$$
\begin{gathered}
g_{e q_{q}}(\theta)= \begin{cases}g_{q 1} & 0 \leq \theta<\theta_{1} \\
g_{q 2} & \theta_{1} \leq \theta<\theta_{2} \\
g_{q 3} & \theta_{2} \leq \theta<\theta_{3} \\
g_{q 4} & \theta_{3} \leq \theta<\theta_{4} \\
g_{0} & \theta_{4} \leq \theta<\frac{2 \pi}{P / 2}\end{cases} \\
g_{e q_{d}}(\theta)= \begin{cases}g_{d 1} & 0 \leq \theta<\theta_{1} \\
g_{d 2} & \theta_{1} \leq \theta<\theta_{2} \\
g_{d 3} & \theta_{2} \leq \theta<\theta_{3} \\
g_{d 4} & \theta_{3} \leq \theta<\theta_{4} \\
g_{0}+\frac{A_{0 m} W_{m}}{h_{m} l_{s t} \mu_{r p m}} & \theta_{4} \leq \theta<\frac{2 \pi}{P / 2}\end{cases}
\end{gathered}
$$

where, $g_{q n}$ and $g_{d n}$ represents the airgap lengths along the rotor periphery corresponding to the $n^{\text {th }}$ saturated regions $\left(R_{A 1}-R_{A 4}\right)$ of the rotor.

$$
\begin{gathered}
g_{q n}=g_{0}+\sum_{c=n}^{4} \frac{A_{0 n} g_{c}}{A_{c} \mu_{s a t}} \\
g_{d n}=g_{0}+\sum_{c=n}^{4} \frac{A_{0 n} g_{c}}{A_{c} \mu_{s a t}}+\frac{A_{0 m} W_{m}}{h_{m} l_{s t} \mu_{r p m}}
\end{gathered}
$$

where, $A_{0 n}$ is the area on the rotor surface that the stator flux is passing through from the airgap into the $n^{\text {th }}$ region as shown in Fig. 18 and is given as:

$$
A_{0 n}=\left(\theta_{n}-\theta_{n-1}\right) R_{r} l_{s t}
$$

and, $A_{0 m}$ is the area on the rotor surface that the stator flux is passing through from the airgap into the magnet region during $\mathrm{d}$-axis alignment and is given as:

$$
A_{0 m}=\frac{\pi R_{r} l_{s t}}{p}
$$

The equivalent airgap functions along $\mathrm{q}$ and $\mathrm{d}$ axis are shown in Fig. 19. As the stator current increases with load, the area of region $4\left(R_{4}\right)$ increases, which can be seen by the increasing values of $\theta_{4}$ with the current. Hence, the equivalent airgap along $\mathrm{d}$ and $\mathrm{q}$ axis also changes with a change in stator current. This eventually leads to a change in $L_{d}$ and $L_{q}$ values with a change in stator current.

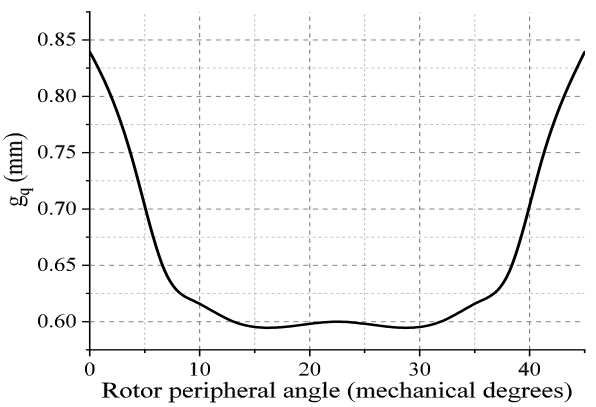

(a)

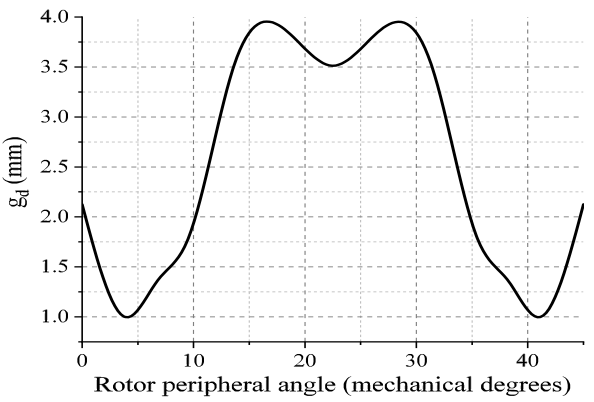

(b)

Fig. 19. Equivalent airgap length at no load: (a) along q-axis (b) along d-axis

\section{B. $L_{d}$ and $L_{q}$ Calculation}

The inductances in three-phase system can be calculated using the airgap function as derived above by [5], [14]:

$$
L_{i j}\left(\theta_{r}\right)=\frac{1}{2}\left(L_{i j q}+L_{i j d}\right)+\frac{1}{2}\left(L_{i j q}-L_{i j d}\right) \cos \left(2\left(\theta_{r}-\theta_{i j}\right)\right)
$$

$$
\begin{aligned}
L_{i j d} & =\int_{0}^{2 \pi} \frac{W_{i}\left(\theta_{r}\right) W_{j}\left(\theta_{r}\right)}{g_{e q_{d}}\left(\theta_{r}\right)} d \theta_{r} \\
L_{i j q} & =\int_{0}^{2 \pi} \frac{W_{i}\left(\theta_{r}\right) W_{j}\left(\theta_{r}\right)}{g_{e q_{q}}\left(\theta_{r}\right)} d \theta_{r}
\end{aligned}
$$

where, $W_{i}\left(\theta_{r}\right)$ is the winding function of $i^{t h}$ phase, and $g_{e q_{d}}$ and $g_{e q_{q}}$ are the equivalent airgap functions along $\mathrm{d}$ and $\mathrm{q}$ axis, respectively, as derived above. The three phase inductance matrix are transformed to get the $\mathrm{d}$ and $\mathrm{q}$ axis inductances [14].

The variation of $L_{d}$ and $L_{q}$ with current obtained using the analytical model is compared with that obtained from experiment and FEA using three phase excitation ckt. The inductance values measured using three phase excitation ckt. as shown in Fig. 20 are more accurate [7]. The plots of $L_{q}$ 


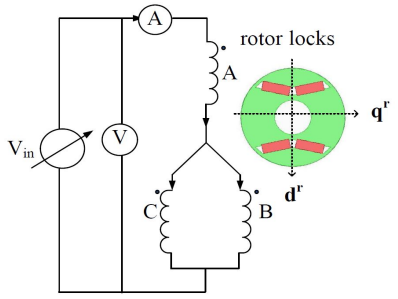

(a)

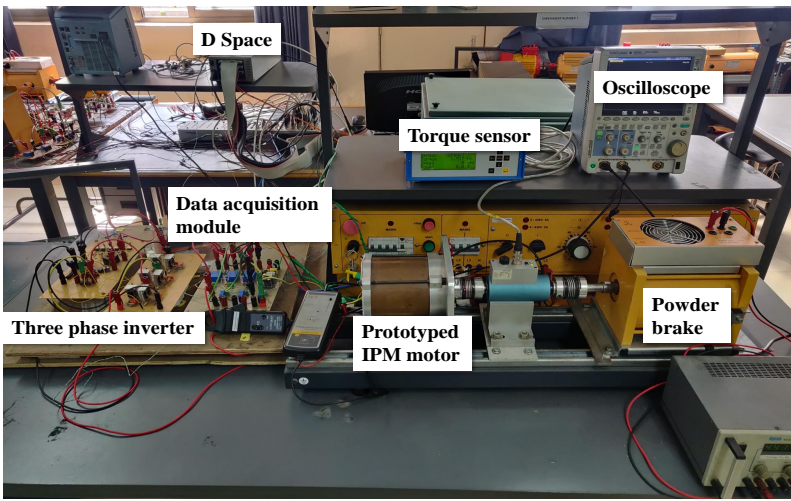

(b)

Fig. 20. Inductance measurement using three phase excitation ckt. (a) Three phase excitation ckt. (b) Experimental set-up.

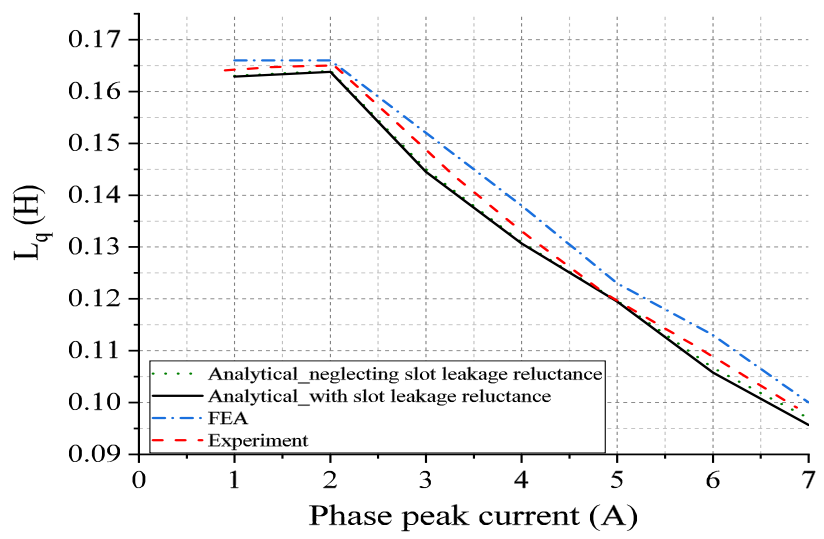

(a)

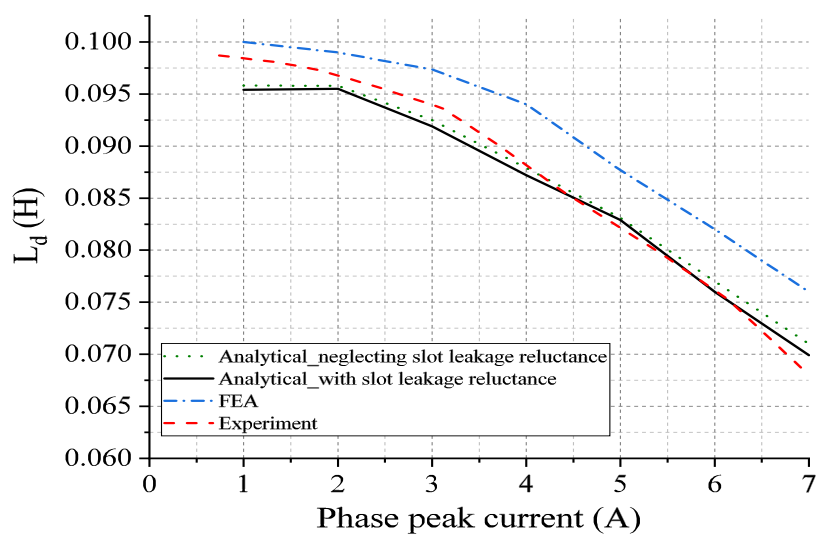

(b)

Fig. 21. Inductance variation with stator current (a) $L_{q}$ variation during q-axis alignment. (b) $L_{d}$ variation during d-axis alignment. and $L_{d}$ variation obatined using analytical model, experiment and FEA are shown in Fig. 21.

\section{CONCLUSIONS.}

In this work, an analytical model of IPM motor for calculating the inductances as a function of current is presented. The proposed model is a combination of MEC and RSM. It is very simple to use and accurate. It is straightforward to use and accurate. The variation between the analytical and measurement results for $L_{q}$ is $2 \%$, and $L_{d}$ is $4.4 \%$ at a rated current of $4 \mathrm{~A}(\mathrm{rms})$. This model can be used for the initial optimization of motor lamination design.

\section{REFERENCES}

[1] B. Zhang, R. Qu, W. Xu, and J. Li, "A permanent magnet traction machine with wide high efficiency range for ev application," in IECON 2015 - 41st Annual Conference of the IEEE Industrial Electronics Society, Nov 2015, pp. $000457-000463$.

[2] Ying Fan, Chao Tan, Siyu Chen, and Ming Cheng, "Design and analysis of a new interior permanent magnet motor for evs," in 2016 IEEE 8th International Power Electronics and Motion Control Conference (IPEMC-ECCE Asia), May 2016, pp. 1357-1361.

[3] J.-G. Lee, D.-K. Lim, and H.-K. Jung, "Analysis and design of interior permanent magnet synchronous motor using a sequential-stage magnetic equivalent circuit," IEEE Transactions on Magnetics, vol. 55, no. 10, pp. $1-4,2019$

[4] D.-K. Lim, K.-P. Yi, D.-K. Woo, H.-K. Yeo, J.-S. Ro, C.-G. Lee, and H.K. Jung, "Analysis and design of a multi-layered and multi-segmented interior permanent magnet motor by using an analytic method," IEEE Transactions on Magnetics, vol. 50, no. 6, pp. 1-8, 2014

[5] M. Farshadnia, Advanced theory of fractional-slot concentrated-wound permanent magnet synchronous machines. Springer, 2018.

[6] M. Farshadnia, A. Pouramin, R. Dutta, and J. E. Fletcher, "Airgap magnetic field estimation for ipm rotors considering their non-uniform local saturation," in 2017 20th International Conference on Electrical Machines and Systems (ICEMS), 2017, pp. 1-6.

[7] B. Nanda and P. Kumar, "Qualitative and quantitative analysis of different inductance measurement techniques for ipm synchronous machines," IEEE Transactions on Energy Conversion, pp. 1-1, 2021.

[8] G. Liu, Y. Wang, Q. Chen, G. Xu, and D. Cao, "Design and analysis of a new equivalent magnetic network model for ipm machines," IEEE Transactions on Magnetics, vol. 56, no. 6, pp. 1-12, 2020.

[9] J.-J. Lee, J. Lee, and K.-S. Kim, "Design of a wfsm for an electric vehicle based on a nonlinear magnetic equivalent circuit," IEEE Transactions on Applied Superconductivity, vol. 28, 2018.

[10] B. Nanda and P. Kumar, "Analytical model of surface mounted permanent magnet motor for sensitivity analysis under manufacturing tolerances," in 2018 IEEE Power Energy Society General Meeting (PESGM), 2018, pp. 1-5.

[11] M. G. Say, The Performance and Design of Alternating Current Machines: Transformers, Three-phase Induction Motors and Synchronous Machines. Pitman, 1952.

[12] D. C. Hanselman, Brushless permanent magnet motor design. The Writers' Collective, 2003.

[13] C. Mishra, A. Routray, and S. Mukhopadhyay, "A computationally efficient winding function method for calculation of inductances in an asymmetric induction motor," Electric Power Components and Systems, vol. 35, no. 1, pp. 43-61, 2007. [Online]. Available: https://doi.org/10.1080/15325000600815456

[14] R. Krishnan, Permanent magnet synchronous and brushless DC motor drives. CRC press, 2017.

[15] B. Nanda and P. Kumar, "Determination of $d$ and $q$ axes inductances for steady state model analysis of pm motor with non-ideal machine parameters," in 2019 IEEE Transportation Electrification Conference and Expo (ITEC), 2019, pp. 1-6. 